\title{
Comunicação
}

[Communication]

\section{Isolamento de dermatófitos em animais domésticos em Vila Real, Portugal}

\author{
[Dermathophytes isolated from domestic animals in Vila Real, Portugal] \\ A.C. Coelho ${ }^{1,2}$, N. Alegria ${ }^{1}$, J. Rodrigues ${ }^{2}$ \\ ${ }^{1}$ Departamento de Ciências Veterinárias \\ Universidade de Trás-os-Montes e Alto Douro \\ Quinta de Prados \\ 5001-801 Vila Real, Portugal \\ ${ }^{2}$ CECAV Portugal
}

Os dermatófitos são fungos que têm capacidade de invasão dos tecidos queratinizados de seres humanos e outros animais, originando uma infecção denominada de dermatofitose (Kane et al., 1997; Zagnoli et al., 2005). As dermatofitoses causam perdas econômicas significativas em todo o mundo. Os efeitos adversos da infecção centram-se no atraso do crescimento, na desvalorização da pele e nos milhões de dólares anuais que se empregam no seu tratamento (Zrimsek et al., 2003).

Do ponto de vista ecológico, os dermatófitos são classificados em três grupos distintos: antropofílicos, zoofílicos e geofílicos. Os fungos antropofílicos encontram-se restritos aos humanos e raramente infectam os animais (Sinski e Kelley, 1987). Os zoofílicos são, primariamente, isolados em animais, mas podem causar doença em humanos em contato com animais como gato, cão, cavalo, entre outros (Kane et al., 1997; Spiewak e Szostak, 2000). Os geofílicos têm como reservatório o solo e apenas ocasionalmente infectam o homem (Spiewak e Szostak, 2000; Gallo et al., 2005). Taxonomicamente, os dermatófitos classificamse nos gêneros Epidermophyton, Microsporum e Trichophyton (Kane et al., 1997). Em Portugal, existem poucos estudos sobre a freqüência do isolamento de dermatófitos em animais (Dias e Martins, 1981; Bernardo et al., 1989; Pinto, 1993; Bernardo et al., 2005). O presente trabalho teve como principal objetivo verificar a

Recebido em 26 de fevereiro de 2007

Aceito em 26 de maio de 2008

E-mail: accoelho@utad.pt freqüência e a etiologia dos dermatófitos isolados nos animais domésticos em Vila Real, Portugal, durante um período de seis anos.

Realizou-se um estudo retrospectivo (2000-2006) de amostras submetidas à análise micológica por suspeita de dermatofitose, no laboratório de Microbiologia da Universidade de Trás-osMontes e Alto Douro, Portugal. Durante esse período, chegaram ao laboratório 257 amostras de descamações cutâneas e pêlos para serem submetidas a diagnóstico de dermatofitose. As amostras pertenciam a 179 cães, 47 gatos, 18 coelhos, nove cavalos e outros quatro animais (uma gineta, duas ovelhas e uma cabra), e todas eram originárias de áreas de pele com lesões compatíveis com dermatofitose.

Os pêlos e as descamações cutâneas foram examinados para a detecção de elementos fúngicos por meio de exame microscópico direto com hidróxido de potássio a $40 \%$. A preparação foi observada ao microscópio (400x) para verificação da presença de hifas e artrósporos.

Para o isolamento dos dermatófitos, as amostras foram inoculadas em meio de $\mathrm{DTM}^{\circledR 1}$ e ágar Sabouraud Dextrose ${ }^{\mathbb{2} 2}$ suplementado de cicloheximida ${ }^{3}$ e incubadas a $25^{\circ} \mathrm{C}$, em ambiente escuro e úmido, sendo examinadas diariamente durante um mês. A identificação dos dermatófitos foi baseada no exame macroscópico das colônias que cresceram em cultura e no

\footnotetext{
${ }^{1}$ Merck, Ref. 10896

${ }^{2}$ Oxoid, Ref. CM0041.

${ }^{3}$ Sigma, Ref. 7698.
} 
exame microscópico com o lactofenol com azul de algodão. Consideraram-se positivas apenas as amostras em que foi possível obter isolamento de dermatófitos em cultura, independentemente dos resultados obtidos no exame microscópico directo. Sempre que necessário recorreu-se a testes complementares, como a prova da urease. Embora os meios utilizados contivessem cicloheximida, observou-se, em algumas culturas, a presença de fungos contaminantes. No caso dos fungos, identificou-se o gênero e, no dos dermatófitos, a espécie. Os fungos contaminantes foram identificados de acordo com o Veterinary Mycology Laboratory Manual (Hungerford et al., 1998). A identificação dos dermatófitos baseou-se na chave de identificação do Laboratory Handbook of Dermathophytes (Kane et al., 1997).

Os dados foram processados nos programas informáticos SPSS $^{\circledR}$. Realizou-se a análise estatística recorrendo ao teste de qui-quadrado para comparar diferenças entre grupos independentes. $\mathrm{O}$ nível de probabilidade
$(\mathrm{P})<0,05$ foi considerado estatisticamente significativo.

Do total das amostras, 69,6\% pertenciam a cães, $18,3 \%$ a gatos, $7,0 \%$ a coelhos, $3,5 \%$ a cavalos e as outras $(1,6 \%)$ distribuíram-se por vários animais como gineta, cabra e ovelhas. Foram isolados dermatófitos em $8,4 \%$ das amostras provenientes dos cães, $21,3 \%$ das amostras de gatos, $66,7 \%$ de coelhos e $11,1 \%$ de cavalos, e não se isolaram dermatófitos dos outros animais. Das 257 amostras cultivadas, 38 (14,8\%) tiveram resultado positivo. As diferenças foram significativas $(\mathrm{P}<0,001)$. No exame microscópico direto, nove $(3,5 \%)$ foram consideradas positivas, embora apenas se tenha obtido isolamento em quatro. A Tab. 1 apresenta o número e a percentagem de amostras positivas no diagnóstico de dermatófitos das amostras provenientes de animais suspeitos de dermatofitose, agrupadas de acordo com o animal hospedeiro. Não se encontraram diferenças significativas entre os resultados da cultura e o sexo dos animais, dos quais provinham as amostras $(\mathrm{P}=0,340)$.

Tabela 1. Freqüência dos dermatófitos isolados a partir de amostras clínicas de animais domésticos em Vila Real (2000-2006)

\begin{tabular}{lccccc}
\hline \multirow{2}{*}{ Dermatófito } & Total & Cão & Gato & Coelho & Cavalo \\
\cline { 2 - 6 } & $\mathrm{n}(\%)$ & $\mathrm{n}(\%)$ & $\mathrm{n}(\%)$ & $\mathrm{n}(\%)$ & $\mathrm{n}(\%)$ \\
\hline Microsporum canis & $18(47,4 \%)$ & $9(60 \%)$ & $9(90 \%)$ & 0 & 0 \\
M. gypseum & $6(15,8 \%)$ & 0 & 0 & $6(50 \%)$ & 0 \\
$\begin{array}{l}\text { M. nanum } \\
\text { Trichophyton }\end{array}$ & $2(5,3 \%)$ & 0 & $1(10 \%)$ & 0 & $1(100 \%)$ \\
mentagrophytes & $12(31,5 \%)$ & $6(40 \%)$ & 0 & $6(50 \%)$ & 0 \\
Total & 38 & 15 & 10 & & 12 \\
\hline
\end{tabular}

Isolaram-se 52 amostras contaminadas com fungos saprófitas (Tab. 2).

Tabela 2. Frequência dos fungos contaminantes isolados a partir de amostras clínicas de animais domésticos em Vila Real (2000-2006)

\begin{tabular}{lc}
\hline Fungo contaminante & $\mathrm{n}(\%)$ \\
\hline Alternaria spp. & $24(46,2 \%)$ \\
Aspergillus spp. & $8(15,4 \%)$ \\
Penicillium spp. & $9(17,3 \%)$ \\
Scopulariopsis spp. & $8(15,4 \%)$ \\
Mucor spp. & $3(5,7 \%)$ \\
Total & $52(20,2 \%)$ \\
\hline
\end{tabular}

A prevalência variou consoante a espécie, atingindo o seu valor mais elevado em coelhos. A percentagem mais baixa ocorreu em cães. A baixa frequência de isolamento nessa espécie, com lesões suspeitas, encontra-se bem documentada na literatura. A percentagem de isolamento obtida neste estudo foi inferior às apresentadas por outros autores que encontraram prevalência de $14-15 \%$ em canídeos (Cabañes et al., 1997; Bernardo et al., 2005). Das amostras analisadas, apenas uma pequena percentagem revelou-se positiva no exame microscópico

${ }^{4}$ SPSS Inc. - Chicago III, EUA, 2000. 
direto. Este método não se apresentou como de grande valia no diagnóstico de dermatofitose.

O elevado número de culturas negativas pode ser explicado pelo fato de muitas dessas amostras serem provenientes de lesões suspeitas, ou porque que os clínicos solicitassem análise apenas para diagnóstico diferencial dos casos dúbios (Cabañes et al., 1997). Os resultados deste estudo confirmam os encontrados antes, que identificaram $M$. canis como o dermatófito mais freqüentemente isolado em animais domésticos, sendo responsável por $95 \%$ das dermatofitoses em gatos e $65 \%$ das infecções em cães (Moriello e Deboer, 1991; Cabañes et al., 1997; Bernardo et al., 2005). Nos cães com lesões suspeitas, $M$. canis é considerado como o fungo mais frequentemente isolado (Cabañes et al., 1997). Neste estudo, M. canis também foi o dermatófito mais freqüentemente isolado nas amostras de cães. Vários estudos citam que a freqüência de isolamento de dermatófitos é cerca de $20 \%$ mais elevada em gatos que em cães (Cabañes et al., 1997). No presente estudo, essa espécie de dermatófito também foi mais freqüentemente isolada em gatos que em cães, e o número de culturas positivas em gatos foi relativamente mais elevado que em cães. A única espécie encontrada em equinos foi M. nanum. Nos coelhos, duas espécies foram isoladas e em igual percentagem: T. mentagrophytes e $M$. gypseum. T. mentagrophytes é considerada como a espécie mais freqüentemente isolada em coelhos (Van Cutsen et al., 1985; TorresRodrigues et al., 1992; Cabañes et al., 1997; Van Rooij et al., 2006). Embora o isolamento de $M$. gypseum seja freqüente em canídeos e eqüídeos, e apenas ocasionalmente isolado de coelhos (Wright, 1989), neste estudo essa espécie correspondeu à metade dos isolamentos registados nos leporídeos. As espécies de $T$. mentagrophytes isoladas dos diferentes animais pertenciam à forma granular de $T$. mentagrophytes var. mentagrophytes, positivas no teste da urease (Kane et al., 1997).

Relativamente aos fungos contaminantes mais freqüentemente isolados, os resultados foram semelhantes aos referidos em outros trabalhos (Moriello e DeBoer, 1991; Cabañes et al. 1997; Bernardo et al., 2005).

Como todas as amostras cultivadas eram provenientes de lesões dermatológicas compatíveis com dermatofitose (descamação, eritema, alopécia), a baixa taxa de isolamento parece um reflexo da dificuldade de se efetuar um diagnóstico apenas com base nas lesões.

Palavras-chave: dermatófitos, animais domésticos, diagnóstico, isolamento

\begin{abstract}
During a six-year period from 2000 to 2006, 257 animal samples (fur and skin desquamation) were submitted to mycological examination in the Laboratory of Microbiology at the Universidade de Trás-osMontes e Alto Douro, Vila Real, Portugal. Dermathophytes were cultured from 38 of 257 (14.8\%) specimens. Chi-squared test was used to compare differences between independent groups. The most frequent isolated dermathophyte was Microsporum canis (47.4\%). Other isolated dermathophytes were: Trichophyton mentagrophytes var. mentagrophytes (31.5\%), Microsporum gypseum (15.8\%), and Microsporum nanum (5.3\%). The rates of dermathophytes isolation were $8.4 \%$ in dogs; $21.3 \%$ in cats; $66.7 \%$ in rabbits; and in $11.1 \%$ in horses.
\end{abstract}

Keywords: dermathophytes, domestic animals, diagnosis, isolation

\section{REFERÊNCIAS BIBLIOGRÁFICAS}

BERNARDO, F.; LANÇA, A.; GUERRA, M.M. et al. Dermatófitos isolados de animais de companhia (cão e gato), em Lisboa, Portugal (2000-2004). Rev. Port. Cienc. Vet., v.100, p.85$88,2005$.
BERNARDO, F.; MARTINS, H.M.; MENDES, A.M. Rastreio de dermatófitos em animais de companhia em Portugal. Rep. Trab. Lab. Investig. Vet., v.21, p.83-88, 1989.

CABANES, F.J.; ABARCA, M.L.; BRAGULAT, M.R. Dermathophytes isolated 
from domestic animals in Barcelona, Spain. Mycopathologia, v.137, p.107-113, 1997.

DIAS, M.C.; MARTINS, M.L. Dermatomicose em canídeo. Rep. Trab. Lab. Investig. Vet., v.23, p.39-42, 1981.

GALLO, M.G.; LANFRANCHI, P.; POGLAYEN, G. et al. Seasonal 4-year investigation into the role of the alpine marmot (Marmota marmota) as a carrier of zoophilic dermatophytes. Med. Mycol., v.43, p.373-379, 2005.

HUNGERFORD， L.L.; CAMPBELL， C.L.; SMITH, A.R. Veterinary mycology laboratory manual. Ames: Iowa State University, 1998.

KANE, J.; SUMMERBELL, R.; SIGLER, L. et al. Laboratory handbook of dermathophytes. Belmont: Star Publishing, 1997.

MORIELLO, K.A.; DEBOER, D.J. Fungal flora of the coat of pet cats. Am. J. Vet. Res., v.25, p.602-606, 1991.

PINTO, A.P. Contribuição para o estudo epidemiológico das dermatofitias dos carnívoros de companhia. 1993. 147f. Dissertação (Mestrado) - Universidade Técnica de Lisboa, 1993.

TORRES-RODRIGUEZ, J.M.; DRONDA, M.A.; ROSSELL, J. et al. Incidence of dermatophytoses in rabbit farms in Catalonia,
Spain, and its repercussion on human health. Eur. J. Epidemiol., v.8, p.326-329, 1992.

SPIEWAK, R.; SZOSTAK, W. Zoophilic and geophilic dermatophytoses among farmers and non-farmers in Eastern Poland. Ann. Agric. Environ. Med., v.7, p.125-129, 2000.

SINSKI, J.T.; KELLEY, L.M. A survey of dermathophytes isolated from patients in the United States from 1982 to 1984. Mycophatologia, v.98, p.35-40, 1987.

VAN ROOIJ, P.; DETANDT, M.; NOLARD, N. Trichophyton mentagrophytes of rabbit origin causing family incidence of kerion: an environmental study. Mycoses, v.49, p.426-430, 2006.

VAN CUTSEN, J.; VAN GERVEN, F.; GEERTS, H. Treatment with enilconazole spray of dermatophytosis in rabbit farms. Mykosen, v.28, p.400-407, 1985.

WRIGHT, A.I. Ringworm in dogs and cats. $J$. Small Anim. Pract., v.30, p.242-249, 1989.

ZAGNOLI, A.; CHEVALIER, B.; SASSOLAS, B. Dermatophyties et dermatophytes. EMC Pédiatrie, v.2, p.96-115, 2005.

ZRIMSEK, P.; KOSS, J.; PINTER, L. et al. Serum-specific antibodies in rabbits naturally infected with Trichophyton mentagrophytes. Med. Mycol., v.41, p.321-329, 2003. 